Available online at www.eccomasproceedia.org

Eccomas Proceedia COMPDYN (2021) 2852-2862

ECCOMAS

Proceedia
COMPDYN 2021

$8^{\text {th }}$ ECCOMAS Thematic Conference on Computational Methods in Structural Dynamics and Earthquake Engineering

M. Papadrakakis, M. Fragiadakis (eds.) Streamed from Athens, Greece, 28 - 30 June 2021

\title{
THE USE OF INTELLIGENT FACADES FOR UPGRADING ENERGY AND SEISMIC DEMANDS OF EXISTING R/C STRUCTURE
}

\author{
Lazaros Melidis ${ }^{1}$, Efthymios A. Kechagias ${ }^{1}$, Konstantinos Katakalos ${ }^{1}$, George C. Manos ${ }^{1}$ \\ ${ }^{1}$ Aristotle University of Thessaloniki \\ Laboratory of Experimental Strength of Materials and Structures, Thessaloniki, 54124 \\ e-mail: \{lazmelidis; ekechagi; kkatakal; gcmanos\}@civil.auth.gr https://strength.civil.auth.gr
}

\begin{abstract}
The installation of exterior facades made of metal elements in buildings is a dual function application: On one hand it alters the facade, through architectural modifications, and on the other it creates the conditions for the improvement of energy efficiency of the building, utilizing the gap that develops between old and new facade. In order to ensure that the suspension and anchoring system can safely receive both static and dynamic loads, which will strain the construction during its life cycle, it is necessary to carry out a set of controls that will ensure exactly this: the static and anti-seismic adequacy of the used suspension and anchoring system. For this reason, a building consisting of frames was chosen, on the perimeter of which masonry was placed and, then, the metal facades were hung on the masonry, through the use of appropriate joints. Through Dynamic Spectral Analysis and Time History Analysis, the adequacy or not of the suspension system was examined, but also the effects that the system had on the modal, strain and deformation sizes of the building. In the end, it was concluded that the attachment of elements to the facade of the building, although it is done for architectural or other purposes, brings about significant changes in its seismic response and, therefore, must be adequately studied.
\end{abstract}

Keywords: Metal facades, Metal links, Structural Dynamics, Earthquake Engineering, Assessment of dynamic characteristics, Ventilated facade.

ISSN:2623-3347 @ 2021 The Authors. Published by Eccomas Proceedia.

Peer-review under responsibility of the organizing committee of COMPDYN 2021.

doi: $10.7712 / 120121.8679 .19493$ 


\section{INTRODUCTION}

\subsection{Ventilated facades}

In modern times, architectural design invests heavily in facade cladding, considering them often part of the original design of the building but also an appropriate solution in cases of reconstruction or renovation of exterior facades and siding. In addition, facade cladding panels are used as partial interventions in facades, in balcony cladding, fencing or the creation of awnings and blinds. There is a plethora of materials that can be used in facade cladding! Examples include titanium zinc, copper, aluminum, bakelites, HPL (High Pressure Laminates) panels, ceramic tiles and colored fiber reinforced cement boards. A ventilated facade is a construction method whereby a physical separation is created between the outside of the facade and the interior wall of the building. This separation creates an open cavity allowing the exchange of the air contained between the wall and the outer cladding.

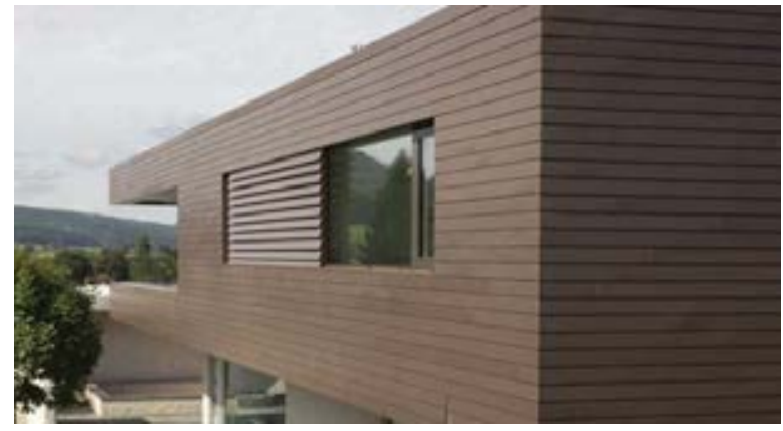

Figure 1: Titanium zinc facade.

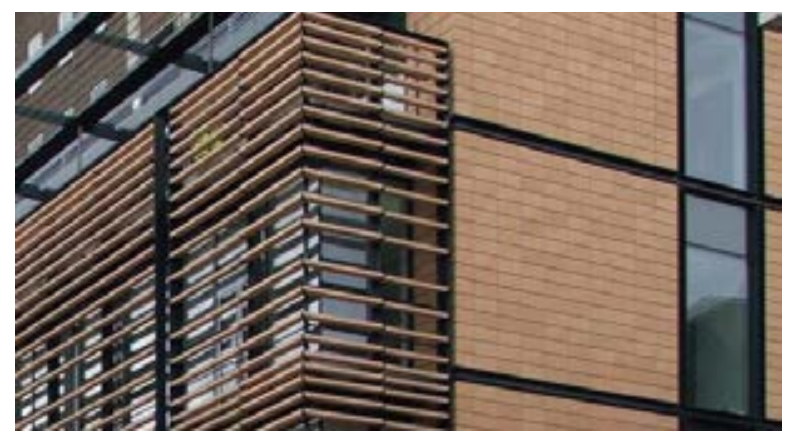

Figure 3: Ceramic tiles facade.

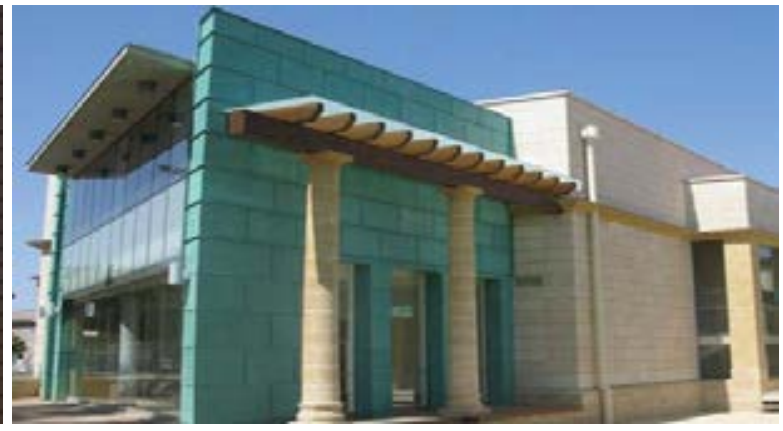

Figure 2: Copper facade.

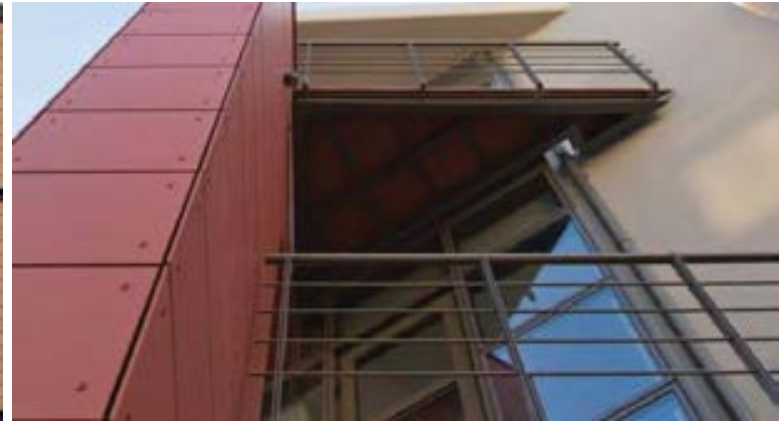

Figure 4: Colored fiber reinforced cement boards facade.

\subsection{Fixing brackets}

To support the facade, a suspension system or fixing brackets system is required. In order for the system in use to be deemed as sufficient, it must first be examined whether the fixing bracket can safely receive the required loads (axial and shear) and then whether it can safely transfer them to the concrete frame and/or masonry infill. Thus, at first, the strength of the fixing bracket is examined, based on the requirements arising from the analysis model and depending on the specifications set by the bracket's manufacturer. It is then checked whether these requirements are covered by the capacities set by the regulations, in this case KAN.EPE. 


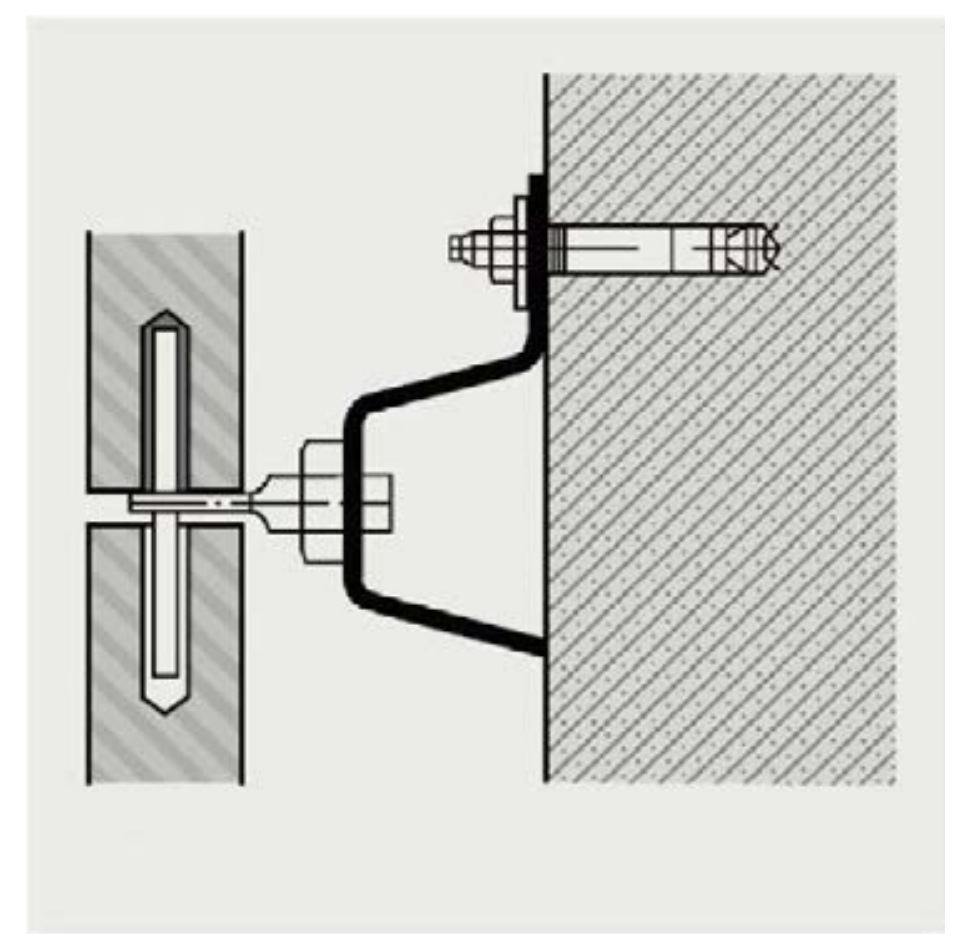

Figure 5: Fixing bracket.

\section{BUILDING GEOMETRY AND CHARACTERISTICS}

The external dimensions of the building are $22.20 \times 22.20 \mathrm{~m}$. In the direction of the X-axis there are 6 frames, with a net opening of $17.00 \mathrm{~m}$ and a distance of $3.50 \mathrm{~m}$ between them. The columns have dimensions $1.10 \times 0.30 \mathrm{~m}$, with the large dimension parallel to the $\mathrm{X}$-axis. The class of the concrete used was evaluated, in current terms, in category C20 / 25 and the reinforcement steel in S135 / 150 [1]. The building has previously been deemed in need of seismic reinforcement [1].

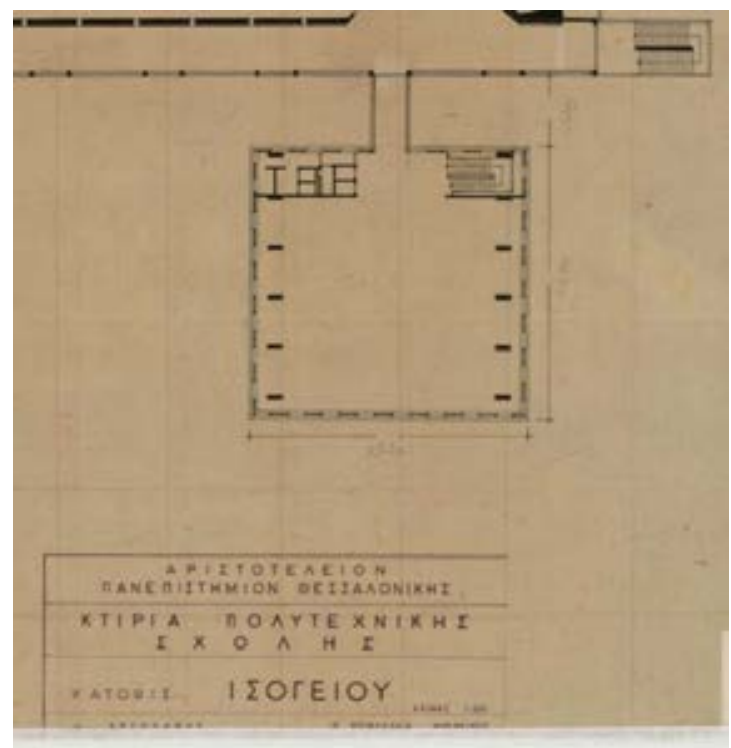

Figure 6: Ground floor plan. 


\section{ANALYSIS}

\subsection{Analysis Methods}

To assess the dynamic characteristics of the building, the Dynamic Spectral Analysis was applied in a fully elastic model, in order to evaluate the adequacy of the support joints and the anchoring system. Furthermore, a Dynamic Time History Analysis was performed on an elastic-partially plastic, non-linear model, in which the joints would yield if they exceeded a certain limit, in order to better analyze the response of the structure in an earthquake scenario.

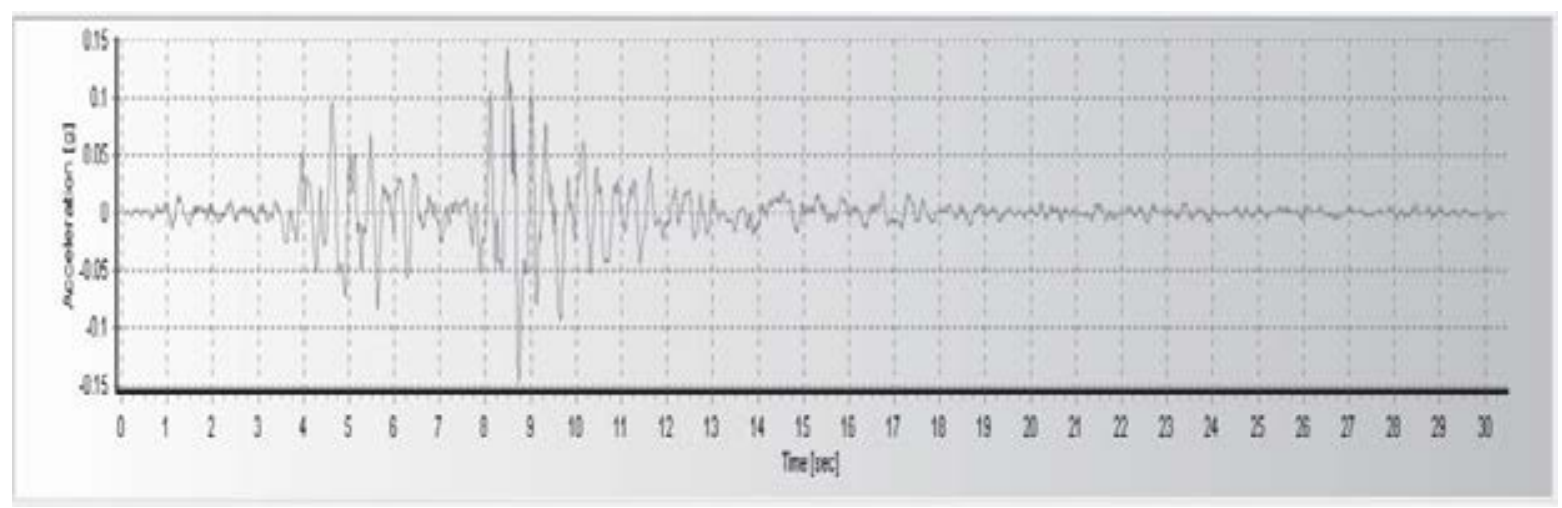

Figure 7: Accelerometer of the Thessaloniki earthquake of 1978.

The E.C. 8 [2] spectrum was used for the Dynamic Spectral Analysis as well as the spectrum obtained from the accelerometer of the 1978 Thessaloniki earthquake. The accelerometer of the Thessaloniki earthquake of 1978 was used for the Dynamic Time History Analysis. The area of Thessaloniki is categorized as ground type B, where ag $=0.16 \mathrm{~g}$. The accelerometer was obtained from a ground type $\mathrm{D}$ area and therefore had to be properly adjusted to ground category $\mathrm{B}$, in order to be compatible with the soil conditions present at the building site. Below, a graph showcasing the acceleration expressed in $\mathrm{g}$ in regard to the oscillation period is depicted, for the spectrum of E.C. 8 in ground category B, as well as the spectrum obtained from the accelerometer for ground category D and ground category B.

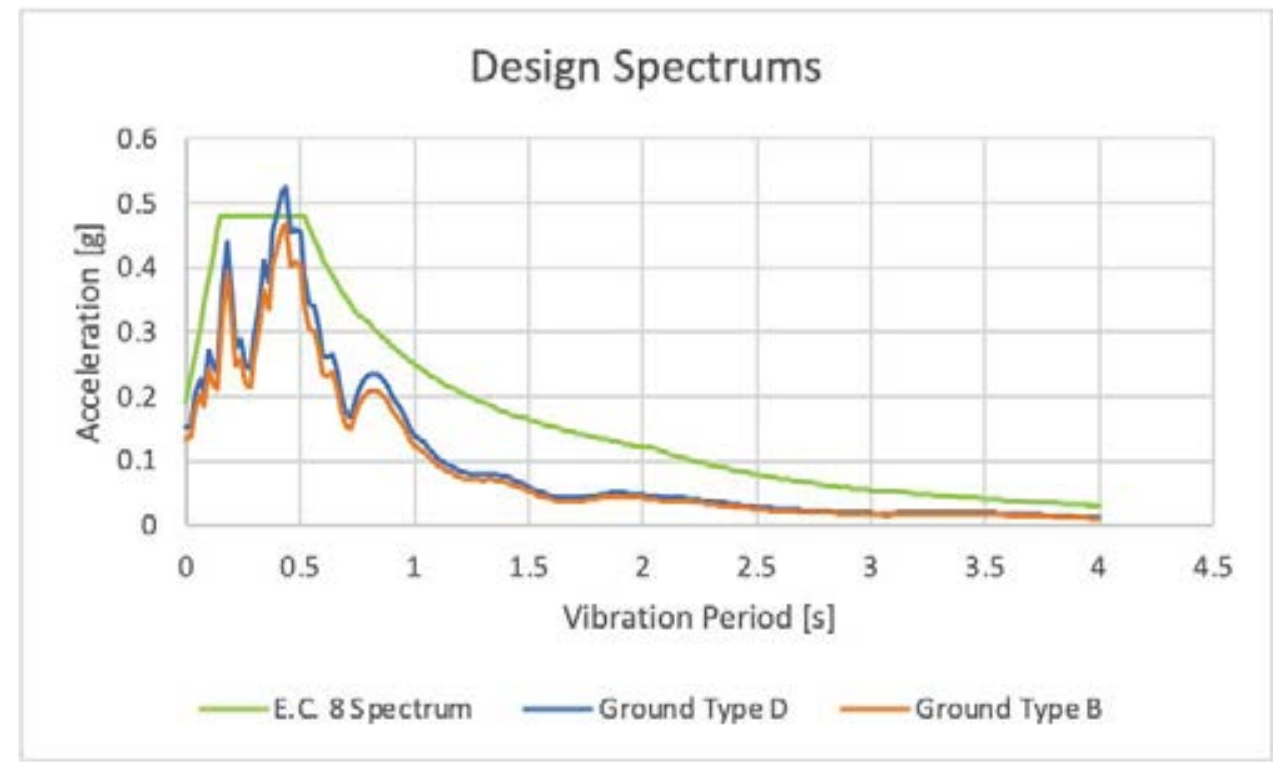

Figure 8: Design Spectrums used in analysis. 


\subsection{Analysis Models}

Three analysis models were used:

- The first model consisted mainly of linear elements, beams and columns, which simulates the current state of the building.

- In the second model, a perimeter of filling masonry was added, in order for the metal facades to be added in a later state, which was also the reference model for the comparisons made.

- In the third model the metal facades were added and comparisons were made.

The analyzes were performed with the help of SAP2000.

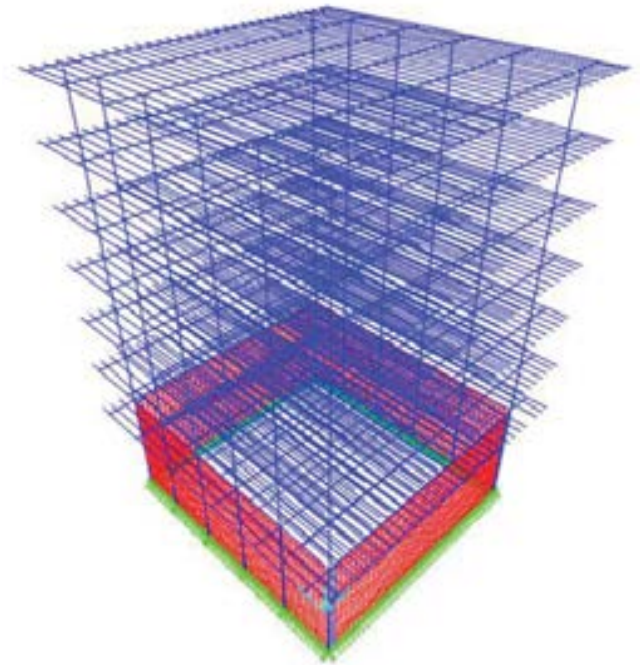

Figure 9: Basic linear model.

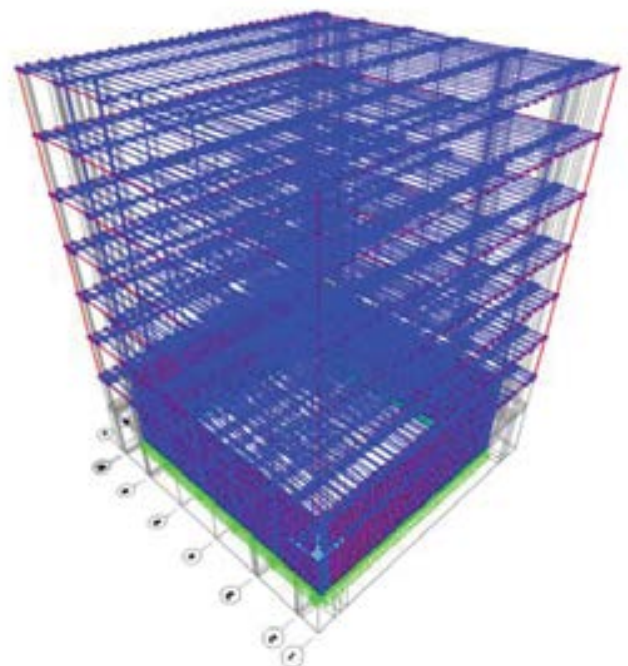

Figure 10: Masonry infilled model.

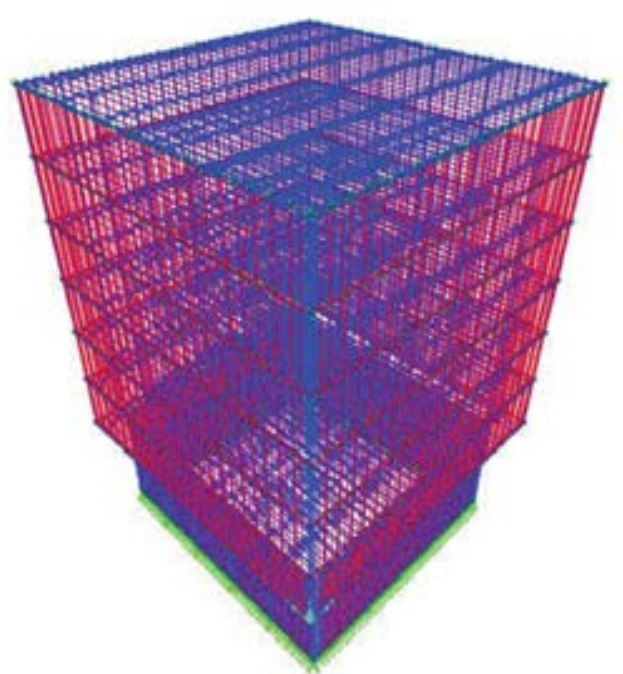

Figure 11: Metal facade model.

\subsection{Vibration Periods}

A sufficient number of eigenmodes was used for each scenario during the analysis. For the first case 6 eigenmodes were used, which activated $60 \%$ of the oscillating mass. For the second case 9 eigenmodes were used, which activated $60 \%$ of the oscillating mass. For the third case, significantly more eigenmodes were needed, a total of 30 , due to the excessive 
number of elements added by the exterior facades. The activated mass in this case amounted to $55 \%$ of the oscillating mass. Appropriate multiplying factors were used in the Dynamic Spectral Analysis, according to the specifications of E.C. 8 to accommodate the activated oscillating mass.

\begin{tabular}{|c|c|c|c|}
\hline \multirow{2}{*}{ Eigenmode } & \multicolumn{3}{|c|}{ Vibrating Period [s] } \\
\cline { 2 - 4 } & Without masonry & With masonry & With facades \\
\hline $\mathbf{1}$ & 2.179 & 0.717 & 0.453 \\
\hline $\mathbf{2}$ & 2.136 & 0.687 & 0.423 \\
\hline $\mathbf{3}$ & 1.634 & 0.285 & 0.391 \\
\hline $\mathbf{4}$ & 0.689 & 0.177 & 0.390 \\
\hline $\mathbf{5}$ & 0.591 & 0.168 & 0.383 \\
\hline $\mathbf{6}$ & 0.494 & 0.161 & 0.376 \\
\hline $\mathbf{7}$ & - & 0.112 & 0.376 \\
\hline $\mathbf{8}$ & - & 0.111 & 0.374 \\
\hline $\mathbf{9}$ & - & 0.097 & 0.370 \\
\hline $\mathbf{2 0}$ & - & - & 0.244 \\
\hline $\mathbf{3 0}$ & - & - & 0.171 \\
\hline
\end{tabular}

Table 1: Vibrating Periods for analysis scenarios.

It is worth noting that the first model is very flexible, which leads to high vibrating periods and low spectral accelerations. The addition of masonry infill leads to a significant reduction of the vibrating period. Furthermore, the addition of metal facades makes the building even more rigid and leads to the development of maximum spectral accelerations, according to E.C. 8 .

\section{ANALYSIS RESULTS}

\subsection{Base shear}

For each scenario, the base shear was calculated in both directions, as the base reaction from the analysis.

\begin{tabular}{|l|c|c|c|}
\hline \multirow{2}{*}{\multicolumn{1}{|c|}{ Case }} & \multicolumn{3}{|c|}{ Base Reaction [kN] } \\
\cline { 2 - 4 } & Without masonry & With masonry & With facades \\
\hline E.C.8-X & 5128 & 13969 & 24625 \\
\hline E.C.8-Y & 5524 & 14740 & 21857 \\
\hline Thess-X & 3117 & 8861 & 27597 \\
\hline Thess-Y & 2744 & 9703 & 21221 \\
\hline
\end{tabular}

Table 2: Base reactions for analysis scenarios.

With the addition of the masonry infill the base reaction almost triples. The addition of the metal facades further doubles the base reaction, in the case of E.C. 8, and triples it in the Thessaloniki 1978 scenario.

\subsection{Reference column strain}

In order to assess the influence that the metal facade has on the seismic response of the building, a corner column was used as a reference point. The axial, shear and moment that was calculated in each scenario was compared, at the level of each floor. 


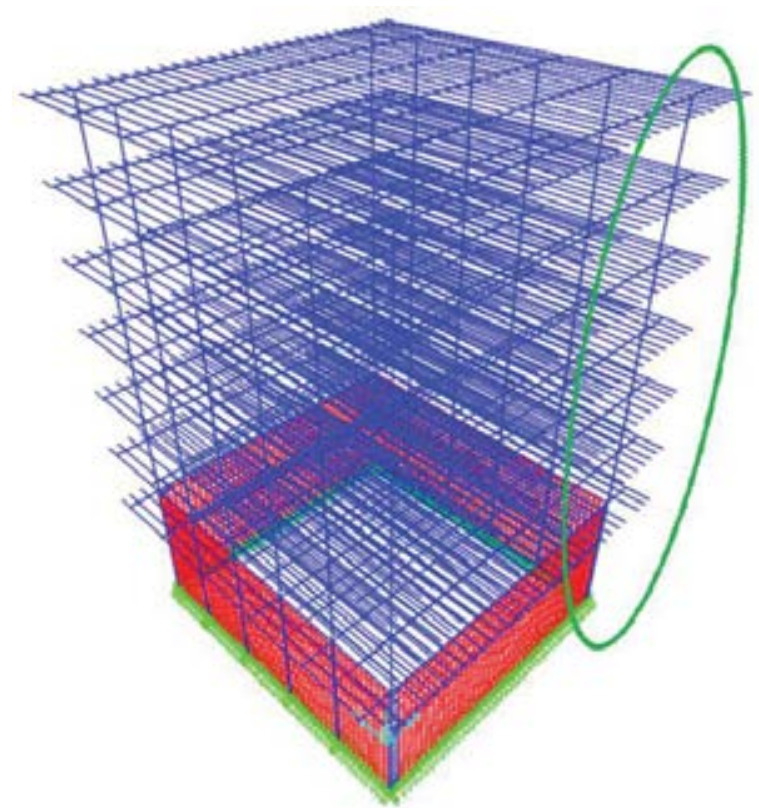

Figure 12: Metal facade model.

The addition of masonry infill multiplied the axial load by an average factor of 6 , while the shear and moment loads dropped by $50 \%$ in average. This was due to the redistribution of strain to the intermediate columns.

The addition of the metal facades had almost no effect to the axial load, but it increased the shear and moment loads by $35 \%$ in average.

\subsection{Reference column top displacement}

The top displacement for the first model was relatively high, mainly due to the low stiffness of the building. The second model, although with a higher base shear, developed a lesser top displacement, due to the increased stiffness offered by the masonry infill. The third model had slightly increased top displacement, due to the higher base shear and the fact that the facades did not contribute significantly to the stiffness of the model.

\begin{tabular}{|l|c|c|c|}
\hline \multirow{2}{*}{\multicolumn{1}{|c|}{ Case }} & \multicolumn{3}{|c|}{ Top displacement [cm] } \\
\cline { 2 - 4 } & Without masonry & With masonry & With facades \\
\hline E.C.8-X & 17.8 & 8.7 & 7.0 \\
\hline E.C.8-Y & 15.6 & 8.4 & 7.0 \\
\hline Thess-X & 14.5 & 5.1 & 7.8 \\
\hline Thess-Y & 12.4 & 5.3 & 6.8 \\
\hline
\end{tabular}

Table 3: Top displacements for analysis scenarios.

\section{ASSESSMENT OF BEARING CAPACITY}

\subsection{Fixing brackets}

The manufacturer's strengths were taken for the assessment of bearing capacity and were compared with the results of the analysis. For a $2 \mathrm{~mm}$ displacement, the bracket was considered to have failed. 


\begin{tabular}{|c|c|c|c|c|c|c|}
\hline \multirow[b]{2}{*}{ Code } & \multirow[b]{2}{*}{ Type } & \multirow[b]{2}{*}{ Size(nm) } & \multirow[b]{2}{*}{ Support } & \multirow[b]{2}{*}{$\begin{array}{l}\text { Loading } \\
\text { direction }\end{array}$} & \multicolumn{2}{|c|}{ Loadbearing capacity } \\
\hline & & & & & $\begin{array}{l}\text { At elastic behavior } \\
\text { of material (vithout } \\
\text { residual displacement) }\end{array}$ & At displacenent $2 \mathrm{~mm}$ \\
\hline $\begin{array}{l}\text { ET710001.00 } \\
\text { (07vario072) }\end{array}$ & double & $62 / 60 / 160$ & fined & vertical & $6,60 \mathrm{kN}$ & $16,45 \mathrm{kN}$ \\
\hline $\begin{array}{l}\text { ET710002.00 } \\
\text { [07variog82) }\end{array}$ & double & $62 / 75 / 160$ & fored & horizontal & $6,07 \mathrm{kN}$ & $10,86 \mathrm{kN}$ \\
\hline $\begin{array}{l}\text { ETm170002.00 } \\
\text { (07varioCB2) }\end{array}$ & double & $62 / 75 / 160$ & movable & horizontal| & $5,06 \mathrm{kN}$ & $10,95 \mathrm{kN}$ \\
\hline $\begin{array}{l}\text { ET710002.00 } \\
\text { (07varioc82) }\end{array}$ & double & $62 / 75 / 160$ & fixed & vertical & $6,04 \mathrm{kN}$ & $10,33 \mathrm{kN}$ \\
\hline $\begin{array}{l}\text { IT710003.00 } \\
\text { (07variodocit) }\end{array}$ & double & $60 / 100 / 160$ & fined & verfical & $6.65 \mathrm{kN}$ & $7.03 \mathrm{kN}$ \\
\hline $\begin{array}{l}\text { ET710003.00 } \\
\text { (07variod102) }\end{array}$ & double & $60 / 100 / 160$ & fixed & horizontal & $1,65 \mathrm{kN}$ & $6,38 \mathrm{kN}$ \\
\hline $\begin{array}{l}\text { ET7100005.00 } \\
\text { (07variodis2) }\end{array}$ & double & $60 / 150 / 160$ & fored & vertical & $3,67 \mathrm{kN}$ & $5,03 \mathrm{kN}$ \\
\hline $\begin{array}{l}\text { ET7no004.00 } \\
\text { (07variodin2) }\end{array}$ & double & $60 / 125 / 160$ & fixed & vertical & $3,42 \mathrm{kN}$ & $6,67 \mathrm{kN}$ \\
\hline $\begin{array}{l}\text { ET710006.00 } \\
\text { (07variodin2) }\end{array}$ & double & $60 / 125 / 160$ & fored & horizontal & $5,17 \mathrm{kN}$ & $10,93 \mathrm{kN}$ \\
\hline $\begin{array}{l}\text { ET710004.00 } \\
\text { (07varicalmz) }\end{array}$ & double & $60 / 125 / 160$ & movable & horizontal & $7.15 \mathrm{kN}$ & $10,15 \mathrm{kN}$ \\
\hline $\begin{array}{l}\text { ET710016 .00 } \\
\text { (07variods) }\end{array}$ & single & $60 / 180 / 90$ & fixed & vertical & $0,33 \mathrm{kN}$ & $0,46 \mathrm{kN}$ \\
\hline $\begin{array}{l}\text { ETm0006.00 } \\
\text { (07variodis2) }\end{array}$ & double & $60 / 180 / 160$ & fued & vertical & $2,40 \mathrm{kN}$ & $3,32 \mathrm{kN}$ \\
\hline $\begin{array}{l}\text { ET7no015.00 } \\
\text { (07vario021) }\end{array}$ & single & $60 / 210 / 90$ & ficed & vertical & $0,36 \mathrm{kN}$ & $0,61 \mathrm{kN}$ \\
\hline
\end{tabular}

Figure 13: Fixing brackets' loadbearing capacities.

\begin{tabular}{|l|c|c|c|c|}
\hline \multirow{2}{*}{ Case } & \multicolumn{2}{|c|}{ Axial } & \multicolumn{2}{c|}{ Shear } \\
\cline { 2 - 5 } & Yields & Failures & Yields & Failures \\
\hline E.C.8-X & 30 & 0 & 88 & 0 \\
\hline E.C.8-Y & 48 & 0 & 10 & 0 \\
\hline Thess-X & 31 & 0 & 90 & 0 \\
\hline Thess-Y & 50 & 0 & 5 & 0 \\
\hline
\end{tabular}

Table 4: Number of brackets yield and failed.

In total, 644 elements were examined. In the worst scenario, 90 of them surpassed the yield limit and none failed.

\subsection{Anchorage system}

The ultimate force under tension the anchor can bear is calculated [3]:

$$
N_{u d}=\pi \cdot d \cdot l_{b} \cdot f_{b d}
$$

Where $N_{u d}$ is the ultimate force under tension the anchor can bear, $d$ the diameter of the anchorage, $l_{b}$ the anchorage length and $f_{b d}$ the tensile strength of the material anchorage takes place.

The ultimate force under shear the anchor can bear is calculated [3]:

$$
F_{u d}=0.65 \cdot d^{2} \cdot \sqrt{f_{c d} \cdot f_{y d}}
$$


Where $F_{u d}$ is the ultimate force under shear the anchor can bear, $d$ the diameter of the anchorage, $f_{c d}$ is the compressive strength of the material anchorage takes place, in this case masonry, and $f_{y d}$ is the steel tensile strength.

For the interaction of the two phenomena the formula used is [3]:

$$
\left(\frac{N_{s d}}{N_{u d}}\right)^{3 / 2}+\left(\frac{F_{s d}}{F_{u d}}\right)^{3 / 2}=1
$$

Where $N_{s d}$ is the axial load from the analysis, $N_{u d}$ is the ultimate force under tension the anchor can bear, as calculated above, $F_{s d}$ is the shear force from the analysis and $F_{u d}$ is the ultimate force under shear the anchor can bear, as calculated above.

All anchorages were deemed sufficient, with the maximum ratio of demand to capacity being $\eta_{\max }=77.4 \%$.

\section{DYNAMIC TIME HISTORY ANALYSIS}

For the Dynamic Time History Analysis, the accelerometer from the earthquake of Thessaloniki of 1978 was used as a ultimate limit scenario and $60 \%$ of it as a serviceability limit scenario, according to KAN.EPE. The links were assigned non-linear properties. Three scenarios were designed, earthquake by the X-axis, earthquake by Y-axis and their SRSS directional combination. Approximately $20 \%$ of the elements surpassed their yield limit during the SRSS directional combination of the ultimate limit scenario. None failed. For the serviceability limit scenario $4 \%$ of the elements surpassed their yield limit during the SRSS directional combination. None failed. In both cases, the brackets used were deemed sufficient.

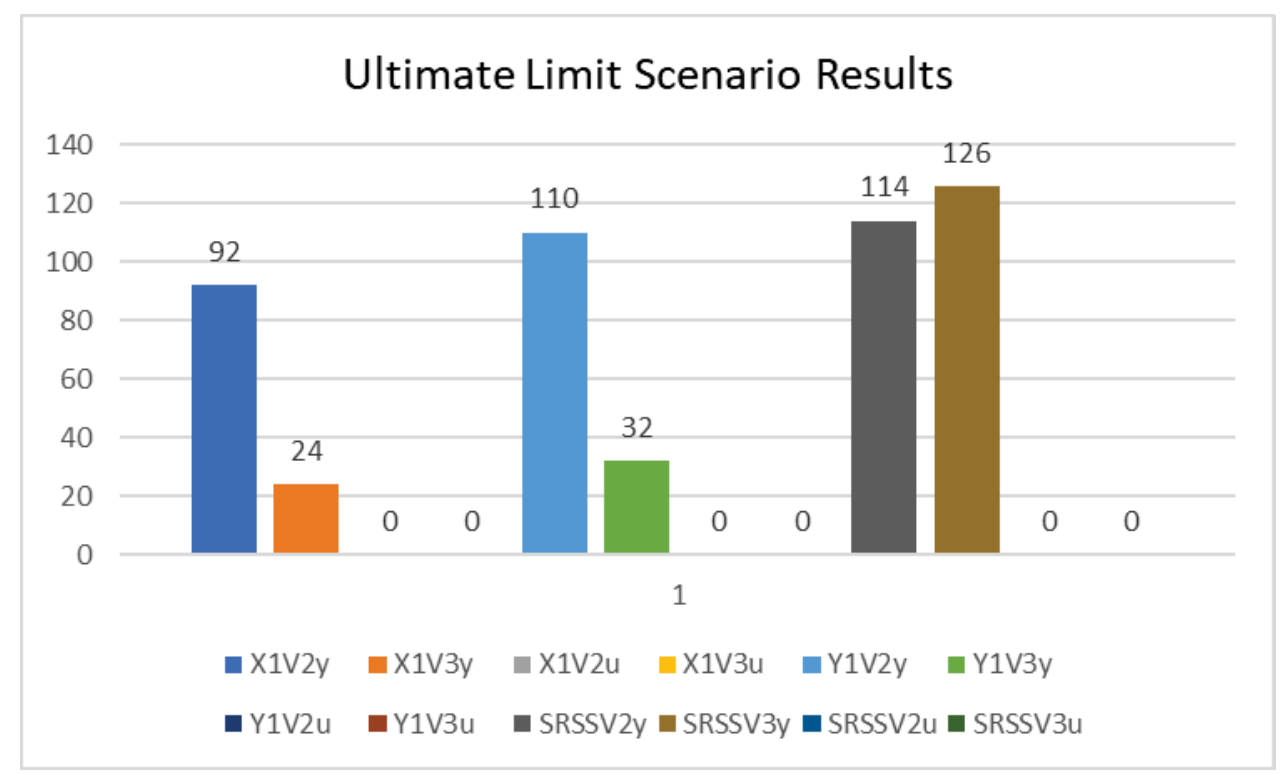

Figure 14: Ultimate Limit Scenario Results. 


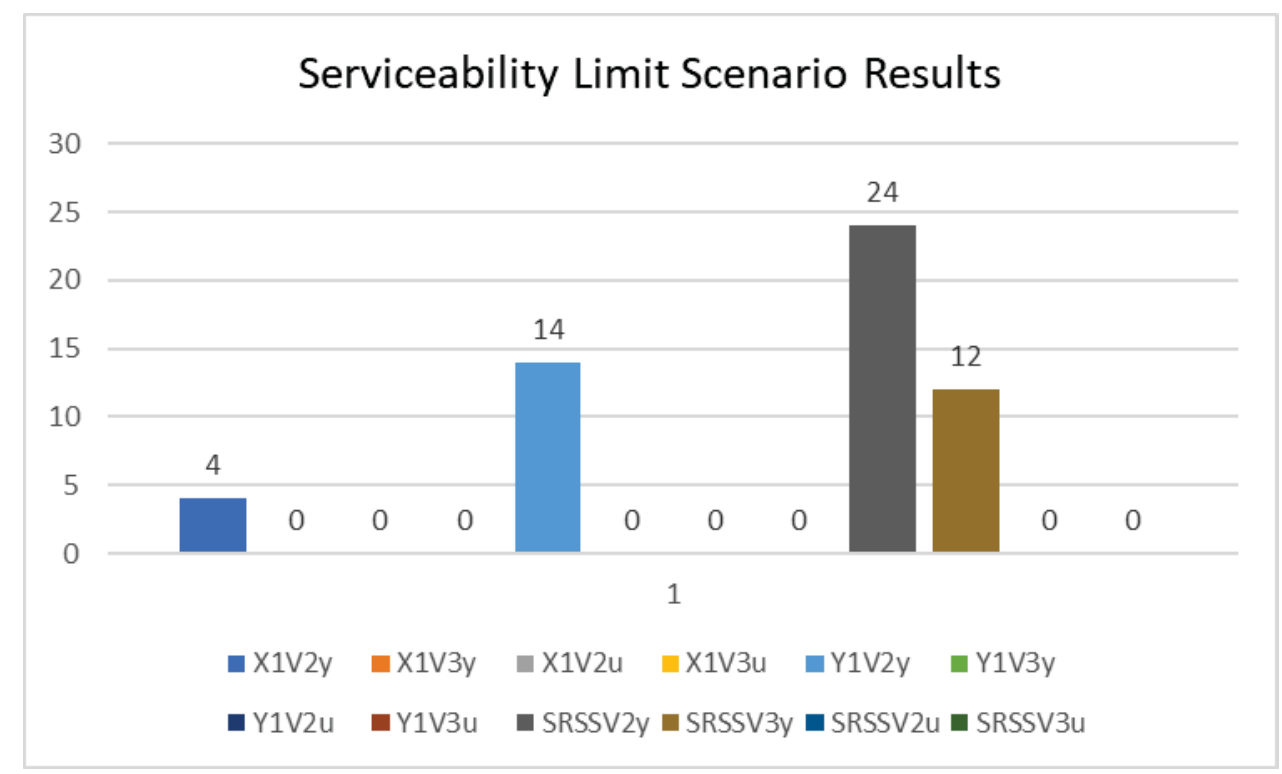

Figure 15: Serviceability Limit Scenario Results.

\section{CONCLUSION}

- The addition of masonry infilled increases the building's stiffness.

- Exterior facades further increase, to a lesser extent, the building's stiffness, the strain developed at the building's frames and its top displacement.

- Retrofitting may be needed in some cases.

- The links used were deemed sufficient.

\section{ACKNOWLEDGMENTS}

Part of the aforementioned research "Intelligent Facades for Nearly Zero Energy Buildings (IF - ZEB)" has been co-funded by Greece and European Union through the Operational Program "Erevno - Dimiourgo - Kainotomo" (project code: T1EDK-02045) which are gratefully acknowledged.

\section{REFERENCES}

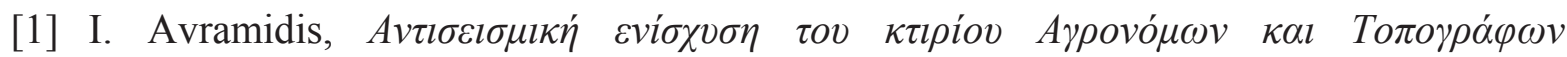

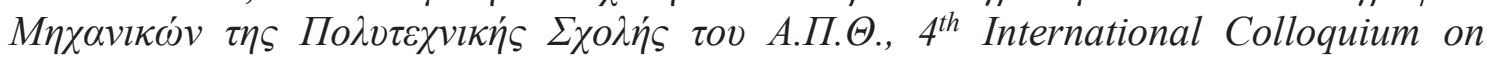
Computation of Shell and Spatial Structures (IASS-IACM 2000), Chania, Crete, Greece, June 4-7, 2000. 
[2] Manos, G.C., Melidis, L., Katakalos, K., Kotoulas, L., Anastasiadis, A., Chatziastrou, C., "Masonry panels with external thermal insulation subjected to in-plane diagonal compression", Case Studies in Construction Materials, Volume 14, June 2021, Article number e00538

[3] G.C.Manos, K.Katakalos, L.Melidis, A.Anastasiadis, "The behaviour of masonry infills with thermal insulation facades under out of plane seismic type loads (in Greek), 4th Panhellenic Conference on Earthquake Engineering and Technical Seismology (2019).

[4] C. Manos, L. Melidis, K. Katakalos, V. Soulis, A. Anastasiadis, Unreinforced masonry with thermal insulation facades in multi-story buildings subjected to seismic type loads, The 17th World Conference on Earthquake Engineering (2020).

[5] P. Antoniadou, M. Symeonidou, E. Kyriaki, E. Giama, S.N. Boemi, S. Chadiarakou, A.M. Papadopoulos, High performance building Facades for Zero Energy Buildings in Greece: state of the art and perspectives, IOP Conference Series: Earth Environ. Sci. 410 (1) (2020), doi:http://dx.doi.org/10.1088/1755-1315/410/1/012036.

[6] A.M. Papadopoulos, State of the art in thermal insulation materials and aims for future developments, Energy Build. 37(1)(2005) 77-86, doi:http://dx.doi.org/10.1016/ j.enbuild.2004.05.006.

[7] European Committee for Standardization (C.E.N.), Eurocode 8, Design of structures for earthquake resistance - Part 1: General rules, seismic actions and rules for buildings. EN 1998-1: 2004E., Brussels, 2004.

[8] Earthquake Planning and Protection Organization (O.A.Е.П.), KAN.EПE., Athens, 2013.

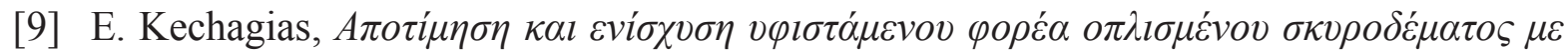

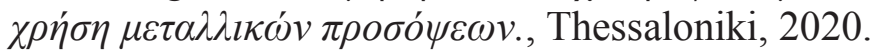

